\title{
ANALISIS RANTAI NILAI SEBAGAI UPAYA UNTUK MENINGKATKAN KEUNGGULAN KOMPETITIF (STUDI KASUS PADA UD. IJEN BATIK BONDOWOSO)
}

\author{
Nia Amelia Damayanti ${ }^{1 *}$, Diyah Probowulan ${ }^{1}$, Ari Sita Nastiti ${ }^{1}$ \\ ${ }^{1}$ Universitas Muhammadiyah Jember, Jl. Karimata No. 49 Jember, Indonesia \\ "Korespondensi: niaameliadamayanti12@gmail.com
}

\begin{abstract}
UD. Ijen Batik Bondowoso is a company engaged in the production of batik for the Bondowoso and surrounding areas, even outside Java and abroad. Competition for batik products in Indonesia makes companies have to increase UD's competitive advantage. Ijen Batik needs to do a strategy. This study aims to analyze the value chain of batik products made at UD. Ijen Batik Bondowoso. Value chain analysis is one way of looking at business as a series of activities that convert inputs into outputs that are of value to customers. This research uses qualitative method with case study method. The type of data used is primary data and secondary data with data collection techniques through observation, interviews and documentation. The results show that the value chain actors consist of suppliers, companies, wholesalers and retailers. In the added value analysis conducted at the time of batik production, it shows an added value of 213,000.00 or 81.3\%/per unit. This is because the highest added value is obtained from sales and marketing activities.
\end{abstract}

Keywords: Value Chain Analysis, Competitive Advantage

\begin{abstract}
ABSTRAK
UD. Ijen Batik Bondowoso merupakan perusahaan yang bergerak di bidang produksi batik untuk wilayah Bondowoso dan sekitarnya bahkan sampai ke luar Jawa dan luar negeri. Kompetisi produk batik diindonesia membuat perusahaan harus meningkatkan keunggulan yang kompetitif UD. Ijen Batik perlu melakukan strategi. Penelitian ini bertujuan untuk menganalisis rantai nilai produk batik yang dibuat di UD. Ijen Batik Bondowoso. Analisis rantai nilai salah satu cara pandang bisnis sebagai serangkaian aktivitas yang mengubah input menjadi output yang bernilai bagi pelanggan. Penelitian ini menggunakan metode kualitatif dengan metode studi kasus. Jenis data yang digunakan adalah data primer dan data sekunder dengan teknik pengumpulan data melalui observasi, wawancara dan dokumentasi. Hasil penelitian menunjukkan bahwa pelaku rantai nilai terdiri dari supplier, perusahaan, wholeseller dan retail. Pada analisis nilai tambah yang dilakukan pada saat produksi batik tulis menunjukkan nilai tambah sebesar 213.000,00 atau 81,3\%/per unit. Hal ini dikarenakan hasil nilai ambah yang tertinggi diperoleh dari aktivitas penjualan dan pemasaran.
\end{abstract}

Kata kunci: Analisis Rantai Nilai, Keunggulan Kompetitif 


\section{PENDAHULUAN}

Kompetisi bisnis saat ini semakin ketat yang disebabkan dengan adanya dampak globalisasi. Era perdagangan bebas telah mengubah model bisnis menjadi keunggulan komparatif dan keunggulan kompetitif, memaksa bisnis untuk memilih strategi yang tepat. Oleh karena itu, perusahaan harus meningkatkan persaingan agar dapat bertahan dalam dunia bisnis. Untuk dapat bersaing dalam dunia bisnis ini, perusahaan harus meningkatkan kinerja perusahaan melalui tata usaha yang lebih baik. Setiap kesenjangan dalam strategi bisnis harus segera diperbaiki untuk kinerja bisnis semakin efektif. Kompetisi yang erat memaksa perusahaan agar lebih meningkatakan daya saingnya. Keunggulan kompetitif menggambarkan kondisi pasar yang dapat memenuhi kebutuhan pelanggan. Karena sifatnya yang cepat dan berkembang, mekanisme keunggulan bersaing sangat responsif. Dalam persaingan bisnis, pemain masih akan berjuang untuk mendapatkan keunggulan kompetitif. Selain itu keunggulan kompetitif dikatakan sensitif karena jika salah menerapkan strategi. Keuggulan kompetitif mengacu pada efisiensi pasar yang kompetitif. Suatu usaha yang dapat menghasilkan produk dan jasa yang baik merupakan usaha yang efisien dalam artian dapat bersaing. (S, 2010)

Analisis rantai nilai (value chain analysis) sangat krusial bagi perusahaan, lantaran melalui analisis rantai nilai, perusahaan bisa memilih banyak sekali tahapan rantai nilai, pada mana perusahaan bisa menambah nilai atau mengurangi porto bagi pelanggan. Pengurangan porto atau nilai tambah (value added) bisa menciptakan perusahaan sebagai lebih kompetitif. Tak hanya itu analisis rantai nilai (value chain analisys) mempunyai laba dimana analisis rantai nilai (value chain analisys) bisa membuat kemampuan perusahaan buat tahu \& mengoptimalkan aktivitas yg membuat keunggulan kompetitif \& taraf laba yg tinggi. Perusahaan bisa membentuk laba pada keliru satu aktivitas melalui analisis rantai nilai yg akan membentuk keunggulan kompetitif \& menaikkan holistik keuntungannya. Untuk membentuk keunggulan kompetitif, sebuah perusahaan memetakan aktivitas spesifiknya pada 5 kegiatan rantai nilai \& mencari cara buat membentuk efisiensi. Analisis rantai nilai memandang perusahaan sebagai salah satu bagian dari rantai produk (Widarsono, 1999).

Agar industri terus berjalan dengan baik membutuhkan sebuat stratefi analisis, yaitu salah satunya analisis SWOT. Analisis SWOT adalah identifikasi sistematis dari berbagai factor yang membentuk strategi perusahaan dan didasarkan pada logika yang memaksimalkan kekuatan dan peluang sekaligus meminimalkan kelemahan dan ancaman (Freddy, 2009).

Menurut Kotler \& Gary (2012), keunggulan kompetitif merupakan keutamaan atas pesaing yg didapat dengan cara memberikan nilai lebih minim juga menggunakan menaruh berguna lantaran harga yang lebih tinggi. Dengan menggunakan teori ini, akan dapat melihat beberapa aspek dimana yang ditawarkan produk dengan nilai lebih rendah tetapi menerima manfaat yang lebih besar. Sedangkan berdasarkan Porter (2013), keunggulan bersaing adalah kecakapan suatu perusahaan untuk menggulungi dalam industry atau pasar yang melalui karakteristik dan sumber daya. Penelitian terkait keunggulan kompetitif telah banyak dilakukan sebelumnya. Suharti \& Yuliawati (2015) meneliti mengenai analisis rantai nilai untuk peningkatan daya saing produk batik. Dalam penelitiannya Suharti \& Yuliawati (2015) menyimpulkan bahwa profit margin dari produk batik bisa ditingkatkan dengan meningkatkan kinerja pengrajin batik secara maksimal yaitu dengan mempertimbangkan peran dari beberapa aktifitas proses usaha batik yakni aktifitas inbound logistic, operation, outbound logistic, marketing and sales, dan service. Selain itu Ayu et al. (2020); Nikmah (2017); 
S (2010); Tindi (2001) juga menganalisis rantai nilai sebagai meningkatkan keunggulan kompetitif.

Perusahaan Ijen Batik adalah perusahaan yg berkecimpung pada bidang produksi batik buat daerah Bondowoso \& sekitarnya bahkan hingga ke luar Jawa \& luar negeri. Berdasarkan wawacara menggunakan Bapak Andriyanto selaku pemilik Ijen Batik, diketahui bahwa perkembangan perusahaan Ijen Batik berdasarkan tahun ke tahun semakin pesat. Akan namun dalam tahun 2019 sampai 2020 UD. Ijen Batik Mengalami penurunan dikarenakan pandemi COVID 19. Tetapi demikian, perusahaan Ijen Batik ini pun mempunyai poly jenis produk batik menggunakan harga yg relatif tinggi jika dibandingkan menggunakan perusahaan lain. Hal itu tentu bisa menyebabkan perkara pada pemasaran mengingat banyaknya produk homogen yg terdapat pada pasaran. Dan dalam akhirnya berdampak dalam volume penjualan.

Berikut merupakan data penjualan produk batik berdasarkan tahun 2017 hingga tahun 2020.

Gambar 1. Data Penjualan Produk Batik dari Tahun 2018 sampai dengan Tahun 2020

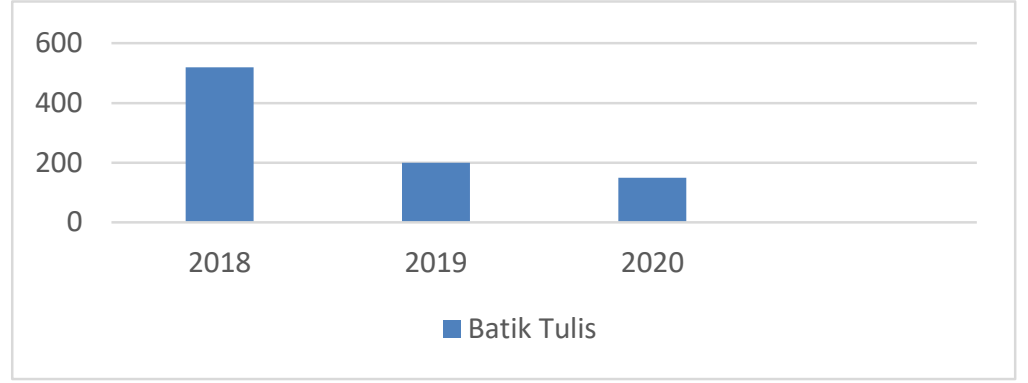

Untuk meningkatkan keunggulan yang kompetitif UD. Ijen Batik perlu melakukan strategi yang tepat. Strategi tidak dapat dilakukan tanpa mengetahui aktivitas apa saja yang ada di UD. Ijen Batik. Agar perusahaan dapat mencapai tujuan tersebut kendala-kendala yang dihadapi oleh perusahaan dapat teratasi tentunya dengan menggunakan pendekatan strategi yaitu analisis rantai nilai.

\section{METODE PENELITIAN}

\section{Jenis Penelitian}

Studi ini menggunakan naratif kualitatif. Dimana dalam studi ini data yang dikumpulkan pada bentuk suatu berita yg tertulis, gambar-gambar, berfikir dan melihat obyek atau kegiatan orang yg terdapat pada sekelilingnya menggunakan melakukan wawancara sebagai akibatnya keadaan yg sesungguhnya bisa tergambar menggunakan baik.

Penelitian Kualitatif menurut Saryono (2010), Penelitian kualitatif adalah penelitian yg dipakai buat menyelidiki, menemukan, menggambarkan, \& mengungkapkan kualitas atau keistimewaan menurut efek sosial yg nir bisa dijelaskan, diukur atau digambarkan melalui pendekatan kuantitatif.

\section{Lokasi Penelitian}

Penelitian yang harus dilakukan peneliti berlokasi pada UD. Ijen Batik yg bertempat pada Bondowoso. Peneliti menentukan lokasi ini lantaran tertarik menggunakan UD. Ijen Batik. Selain itu peneliti ingin mengetahui kegiatan-kegiatan primer yg terdapat pada produksi Ijen Batik melalui analisi rantai nilai (value chain analisys). 


\section{Sumber Data Penelitian}

Menurut Sugiyono (2017) Sumber data penelitian dibagi sebagai dua diantaranya yaitu data utama (primer) dan data sekunder. Sumber data yg dipakai pada penelitian ini merupakan memakai data utama (primer) dan data sekunder.

1. Data Primer

Data primer dalam penelitian ini adalah data yang dihasilkan dari informan secara langsung seperti wawancara langsung dengan pemilik produksi Ijen Batik Bondowoso.

2. Data Sekunder

Data sekunder dalam penelitian ini adalah menggunakan data yang didapat dari berbagai sumber yang tertulis. Subjeknya adalah informan. Dimana informan ini akan menggali informasi terkait dengan perusahaan.

\section{Teknik Pengumpulan Data}

Metode pengumpulan data yang digunakan dalam penelitian ini dilakukan dengan mengumpulkan data sesuai prosedur penelitian. data yang digunakan valid dan akurat. Untuk mengumpulkan data primer peneliti akan melakukan wawancara kepada pihak yang bersangkutan.

\section{Teknik Pengolahan dan Analisis Data}

Dalam studi ini, peneliti melakukan analisis kegiatan-kegiatan pada internal perusahaan. Dalam studi ini peneliti melakukan analisis rantai nilai perusahaan yang berfokus menganalisis aktivitas utama (primer) tahap-tahap dalam melakukan analisis data yaitu:

1. Mengidentifikasi Aktivitas Rantai nilai

2. Mengidentifikasi Cost Driver

3. Menganalisis SWOT

4. Mengembangkan Keunggulan yang lebih kompetitif dengan cara mengurangi biaya atau Menambahkan nilai bagi pelanggan.

5. Kesimpulan

\section{HASIL DAN PEMBAHASAN}

Ijen Batik merupakan sentra industri batik di Bondowoso yang berlokasi di Desa Kemirian, Kecamatan Tamanan, Kabupaten Bondowoso. Pendirian Ijen Batik di pelopori oleh Andriyanto. Pada bulan juli 2017 bapak Andriyanto mendirikan rumah industri batik bersama kedua temannya, yaitu Ervin dan Kholis. Dalam menamai perusahaannya, pemilik sendiri memberikan nama Ijen Batik yang mana terispirasi dari tempat wisata popular di Bondowoso, yaitu Kawah Ijen.

\section{Pemetaan Rantai Nilai}

Gambar dibawah menggambarkan pemetaan rantai nilai yang kegiatan pemasaran produk batik dimulai dari proses produksi hingga sampai ke konsumen akhir yang akan melewati beberapa tahapan dan proses yang berbeda. Berikut keterangan tiga bagian pemetaan rantai nilai yang terdiri dari tiga segmen utama:

1. Segmen Upstream

Segmen Upstream terdiri berdasarkan pemasok yg mencakup bahan standar primer dan bahan baku penunjang. Bahan baku utama dalam pembuatan batik diantaranya kain mori, lilin atau malam, pewarna, dan waterglass. Sedangkan bahan baku penunjang adalah lilin atau malam, pewarna, dan waterglass. 


\section{Segmen Midstream}

Segmen Midstream adalah produsen dalam aktivitas rantai nilai. Ada proses penambah nilai pada bagian ini, seperti preparasi, perekatan lilin, pewarnaan, perlorodan, dan finishing.

3. Segmen Downstream

Semua operasi yang mencakup pengiriman barang ke pelanggan akhir termasuk di bagian hilir. Batik tersebut siap didistribusikan ke penjahit di kawasan Bondowoso setelah proses pembuatan batiknya selesai.
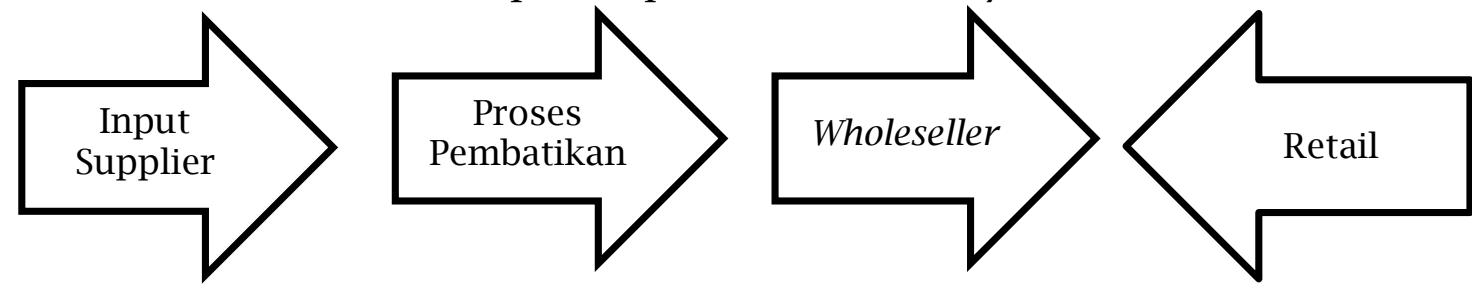

UPSTREAM

MIDSTREAM

DOWNSTREAM
1. Kain mori
2. Malam
3. Pewarna
4. Waterglass

1. Tahap I Persiapan

a. Pemotongan kain mori

b. Mendesain batik

c. Penjiplakan hasil desain

2. Tahap II Perekatan lilin

a. Membatik sesuai pola

b. Nembok.

3. Tahap III Pewarnaan

a. Pewarnaan kain mori yang sudah di pola

b. Melakukan fiksasi

c. Pengeringan

4. Tahap IV Pelodoran

a. Pelodoran atau melepas malam.

5. Finishing
a. Pengeringan
b. Pelipatan
c. Menyetrika
d. packing

\begin{tabular}{|l|}
\hline $\begin{array}{l}\text { Bahan Utama } \\
\text { Kain mori }\end{array}$ \\
\hline \hline Bahan \\
Penunjang \\
1. Lilin/malam \\
2. Pewarna \\
3. Waterglass \\
\hline
\end{tabular}

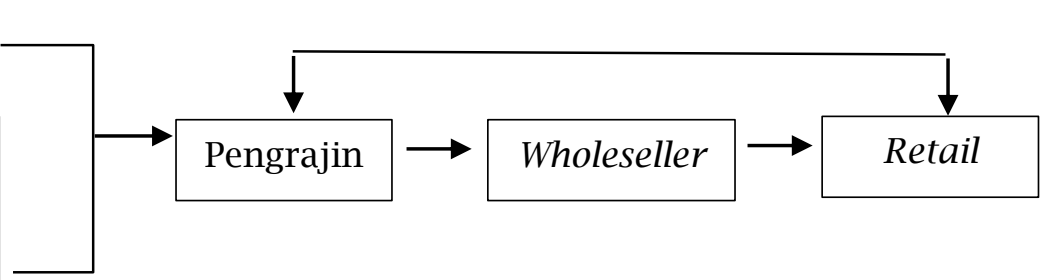

Gambar 2 Pemetaan Rantai Nilai

\section{Pelaku Utama Rantai Nilai}

1. Pemasok

2. Perusahaan

3. Wholeseller

4. Retail 


\section{Analisis Nilai Tambah}

Tabel 1. Jenis Produk Batik

\begin{tabular}{clll}
\hline No. & \multicolumn{1}{c}{ Kategori Batik Tulis } & Kategori Batik Cap & $\begin{array}{c}\text { Kategori Batik } \\
\text { Abstrak }\end{array}$ \\
\hline 1 & Batik tulis motif blue fire & Batik cap motif parang & Batik abstrak \\
2 & Batik tulis motif macan & Batik cap motif batu & \\
3 & $\begin{array}{l}\text { Batik tulis motif daun } \\
\text { singkong } \\
\text { Batik tulis motif bunga } \\
\text { sepatu }\end{array}$ & \\
\hline
\end{tabular}

Berdasarkan Tabel 1 diatas, analisis nilai tambah pada industri Ijen Batik peneliti hanya berfokus pada produk batik tulis dengan memakai beberapa asumsi sebagai berikut :

1. UD. Ijen Batik memproduksi batik tulis sejumlah 5 potong per hari

2. Perhitungan biaya penyusutan menggunakan metode garis lurus

3. Jumlah output yang dihasilkan dihitung seberapa banyak produk batik yang dihasilkan dalam perhari.

Analisis nilai tambah mencakup beberapa komponen yaitu biaya bahan baku, biaya overhead pabrik dan biaya tenaga kerja langsung:

1. Biaya Bahan Baku

Tabel 2. Biaya Bahan Baku Batik Tulis

\begin{tabular}{cccccc}
\hline No & $\begin{array}{c}\text { Jenis } \\
\text { Kain }\end{array}$ & Kuantitas & $\begin{array}{c}\text { Harga } \\
\text { Satuan (Rp) }\end{array}$ & Biaya (Rp) & Biaya/Unit \\
\hline 1. & Kain & $2 \mathrm{~m}$ & 25.000 & 250.000 & 50.000 \\
& $\begin{array}{c}\text { Mori } \\
\text { Jumlah }\end{array}$ & & & $\mathbf{2 5 0 . 0 0 0}$ & $\mathbf{5 0 . 0 0 0}$ \\
\hline
\end{tabular}

\section{Biaya Tenaga Kerja Langsung}

Tabel 3. Biaya Tenaga Kerja Langsung

\begin{tabular}{llllll}
\hline No & Jenis Pekerjaan & Jumlah & Upah/Bulan & Upah/Hari & Upah/Unit \\
\hline 1 & Bagian & 5 & 300.000 & 10.000 & 10.000 \\
2 & Penjiplakan & 3 & 900.000 & 30.000 & 18.000 \\
& Bagian & 3 & 600.000 & 20.000 & 36.000 \\
3 & Pencantingan & & 300.000 & 10.000 & 12.000 \\
4 & Bagian Pewarnaan & 9 & 300.000 & 10.000 & 10.000 \\
5 & Bagian Pelodoran & 5 & $\mathbf{2 . 4 0 0 . 0 0 0}$ & $\mathbf{8 0 . 0 0 0}$ & $\mathbf{8 6 . 0 0 0}$ \\
& Total & & & & \\
\hline
\end{tabular}




\section{Biaya Overhead Pabrik}

a. Biaya Bahan Baku Tidak Langsung

Tabel 4. Biaya Bahan Baku Tidak Langsung

\begin{tabular}{ccccc}
\hline Komponen & Jumlah & Harga & Biaya & Biaya/Unit \\
\hline Lilin atau & 5 & 35.000 & 175.000 & 35.000 \\
malam & 5 & 15.000 & 75.000 & 15.000 \\
Pewarna & 5 & 50.000 & 300.000 & 60.000 \\
Waterglass & 6 & & $\mathbf{5 5 0 . 0 0 0}$ & $\mathbf{1 1 0 . 0 0 0}$ \\
$\quad$ Total & & & & \\
\hline
\end{tabular}

b. Biaya Tidak Langsung

Tabel 5. Beban Penyusutan Peralatan

\begin{tabular}{|c|c|c|c|c|c|c|}
\hline Komponen & $\begin{array}{l}\text { Harga } \\
\text { Awal }\end{array}$ & Jumlah & $\begin{array}{l}\text { Biaya } \\
\text { Residu }\end{array}$ & $\begin{array}{l}\text { Umur } \\
\text { Eko. }\end{array}$ & $\begin{array}{l}\text { Biaya } \\
\text { Penyusutan/th }\end{array}$ & $\begin{array}{l}\text { Biaya } \\
\text { Penyusutan } \\
\text { /Unit }\end{array}$ \\
\hline Canting & 20.000 & 3 & & 2 & 30.000 & 16,7 \\
\hline Kompor & 300.000 & 3 & 100.000 & 3 & $266.666,667$ & 148,1 \\
\hline $\begin{array}{l}\text { Meja } \\
\text { Gambar }\end{array}$ & 750.000 & 2 & 300.000 & 3 & 400.000 & 222,2 \\
\hline $\begin{array}{l}\text { Panci } \\
\text { Lorot }\end{array}$ & 150.000 & 3 & 50.000 & 3 & 133.333,333 & 74,1 \\
\hline Etalase & $\begin{array}{l}2.000 .00 \\
0\end{array}$ & 1 & $\begin{array}{l}1.000 .00 \\
0\end{array}$ & 5 & 200.000 & 111,1 \\
\hline $\begin{array}{l}\text { Tabung } \\
\text { Gas }\end{array}$ & 165.000 & 3 & 100.000 & 2 & 197.500 & 109,7 \\
\hline Setrika & 250.000 & 1 & 150.000 & 3 & 33.333,3333 & 18,5 \\
\hline
\end{tabular}

Tabel 6. Biaya Operasional

\begin{tabular}{lcc}
\hline \multicolumn{1}{c}{ Komponen } & Biaya/Bulan & Biaya/Unit \\
\hline Listrik & 125.000 & 833,33 \\
Air & 60.000 & 0,4 \\
Total & $\mathbf{2 1 0 . 0 0 0}$ & $\mathbf{8 3 3 , 7 3}$ \\
\hline
\end{tabular}

Tabel 7. Biaya Penyusutan Kendaraan

\begin{tabular}{cccccc}
\hline Komponen & Harga Awal & Biaya Residu & $\begin{array}{c}\text { Umur } \\
\text { Eko. }\end{array}$ & $\begin{array}{c}\text { Biaya } \\
\text { Penyusutan/Th }\end{array}$ & $\begin{array}{c}\text { Biaya } \\
\text { Penyusutan/Unit }\end{array}$ \\
\hline Kendaraan & 15.000 .000 & 6.000 .000 & 8 & 1.125 .000 & 625 \\
\hline
\end{tabular}


Tabel 8. Total Biaya Tidak Langsung

\begin{tabular}{clc}
\hline No. & \multicolumn{1}{c}{ Keterangan } & Biaya/Unit \\
\hline 1 & Biaya Penyusutan Peralatan & 18,5 \\
2 & Biaya Operasional & 833,73 \\
3 & Biaya Penyusutan Kendaraan & 625 \\
& Total & $\mathbf{1 . 4 7 7 , 2 3}$ \\
\hline
\end{tabular}

Tabel 9. Biaya Tenaga Kerja Tidak Langsung

\begin{tabular}{cccc}
\hline Komponen & Jumlah & Biaya/bulan & Biaya/unit \\
\hline Gaji & 28 orang & 2.500 .000 & 10.000 \\
\hline
\end{tabular}

Tabel 10. Total Biaya Overhead Pabrik

\begin{tabular}{clc}
\hline No & \multicolumn{1}{c}{ Keterangan } & Biaya/Unit \\
\hline 1 & Biaya bahan baku tidak langsung & 110.000 \\
2 & Biaya tidak langsung & $1.477,23$ \\
3 & Biaya tenaga kerja tidak langsung & 10.000 \\
& Total & $\mathbf{1 2 1 . 4 4 7 , 2 3}$ \\
\hline
\end{tabular}

Tabel 11. Beban Pemasaran

\begin{tabular}{clcc}
\hline No. & Biaya/ bulan & Biaya/bulan & Biaya/unit \\
\hline 1 & Periklanan & 300.000 & 2.000 \\
2 & Transportasi & 300.000 & 2.000 \\
3 & Plastik & 250.000 & $1.666,67$ \\
& Total & $\mathbf{8 5 0 . 0 0 0}$ & $\mathbf{5 . 6 6 6 , 6 7}$ \\
\hline
\end{tabular}

Tabel 12. Beban Administrasi

\begin{tabular}{ccc}
\hline Komponen & Biaya/bulan & Biaya/unit \\
\hline Telepon & 200.000 & 1,33 \\
\hline
\end{tabular}

Tabel 13. Total Beban Komersial

\begin{tabular}{clc}
\hline No & \multicolumn{1}{c}{ Keterangan } & Biaya/unit \\
\hline 1 & Beban Pemasaran & $5.666,67$ \\
2 & Beban Administrasi & 1,33 \\
& Total & $\mathbf{5 . 6 6 8}$ \\
\hline
\end{tabular}


Tabel 14. Perhitungan Nilai Tambah

\begin{tabular}{|c|c|c|c|c|c|c|c|}
\hline No & Jenis Biaya & $\begin{array}{l}\text { Biaya } \\
\text { Terendah }\end{array}$ & $\begin{array}{l}\text { Rata- } \\
\text { rata } \\
\text { Biaya }\end{array}$ & $\begin{array}{l}\text { Biaya } \\
\text { Tertinggi }\end{array}$ & $\begin{array}{l}\text { Rata-rata } \\
\text { Biaya } \\
\text { Produksi } \\
\text { Batik } 2 \\
\text { Meter }\end{array}$ & $\begin{array}{l}\text { Rata- } \\
\text { rata } \\
\text { Harga } \\
\text { Jual } \\
\text { Produk } \\
\text { Batik }\end{array}$ & $\begin{array}{l}\text { Nilai } \\
\text { Tambah } \\
\text { (\%) }\end{array}$ \\
\hline \multicolumn{8}{|c|}{ Biaya Produksi (Biaya Bahan Baku, Biaya Tenaga Kerja, BOP) } \\
\hline 1. & Kain Mori & $\begin{array}{l}\text { Rp. } \\
15.000\end{array}$ & $\begin{array}{l}\text { Rp. } \\
20.000\end{array}$ & $\begin{array}{l}\text { Rp. } \\
25000\end{array}$ & & & $5,4 \%$ \\
\hline 2. & Malam & Rp. 5.000 & $\begin{array}{l}\text { Rp. } \\
10.000\end{array}$ & $\begin{array}{l}\text { Rp. } \\
15.000\end{array}$ & & & $2,7 \%$ \\
\hline 3. & Pewarna & $\begin{array}{l}\text { Rp. } \\
20.000\end{array}$ & $\begin{array}{l}\text { Rp. } \\
30.000\end{array}$ & $\begin{array}{l}\text { Rp. } \\
40.000\end{array}$ & & & $8,2 \%$ \\
\hline 4. & Waterglass & Rp. 5000 & $\begin{array}{l}\text { Rp. } \\
7.500\end{array}$ & $\begin{array}{l}\text { Rp. } \\
10.000\end{array}$ & & & $2,0 \%$ \\
\hline 5. & $\begin{array}{l}\text { Tenaga Kerja } \\
\text { Bagian } \\
\text { Penjiplakan }\end{array}$ & Rp. 5000 & Rp. 750 & $\begin{array}{l}\text { Rp. } \\
10.000\end{array}$ & & & $1,4 \%$ \\
\hline 6. & $\begin{array}{l}\text { Tenaga Kerja } \\
\text { Bagian } \\
\text { Mencanting }\end{array}$ & $\begin{array}{l}\text { Rp. } \\
20.000\end{array}$ & $\begin{array}{l}\text { Rp. } \\
25.000\end{array}$ & $\begin{array}{l}\text { Rp. } \\
30.000\end{array}$ & & & $6,8 \%$ \\
\hline 7. & $\begin{array}{l}\text { Tenaga Keja } \\
\text { Bagian } \\
\text { Pewarnaan }\end{array}$ & $\begin{array}{l}\text { Rp. } \\
10.000\end{array}$ & $\begin{array}{l}\text { Rp. } \\
15.000\end{array}$ & $\begin{array}{l}\text { Rp. } \\
20.000\end{array}$ & & & $5,0 \%$ \\
\hline 8. & $\begin{array}{l}\text { Tenaga Kerja } \\
\text { Bagian } \\
\text { Fiksasi }\end{array}$ & Rp. 5.000 & Rp. 750 & $\begin{array}{l}\text { Rp. } \\
10.000\end{array}$ & & & $1,4 \%$ \\
\hline 9. & $\begin{array}{l}\text { Tenaga Kerja } \\
\text { Bagian } \\
\text { Pelodoran }\end{array}$ & Rp. 5000 & Rp. 750 & $\begin{array}{l}\text { Rp. } \\
10.000\end{array}$ & & & $1,4 \%$ \\
\hline & Rata-rata & iaya Produk & i Batik T & & 109.750 & & \\
\hline 10. & $\begin{array}{l}\text { Bahan } \\
\text { Pendukung }\end{array}$ & Rp. 5.000 & Rp. 750 & $\begin{array}{l}\text { Rp. } \\
10.000\end{array}$ & & & $1,4 \%$ \\
\hline 11. & Listrik & Rp. 3.000 & $\begin{array}{l}\text { Rp. } \\
4.000\end{array}$ & Rp. 5.000 & & & $1,0 \%$ \\
\hline 12. & $\begin{array}{l}\text { Peralatan } \\
\text { (Canting, } \\
\text { Panci Lorot, } \\
\text { Gas) }\end{array}$ & Rp. 5.000 & $\begin{array}{l}\text { Rp. } \\
5.000\end{array}$ & Rp. 5.000 & & & $1,3 \%$ \\
\hline 13. & $\begin{array}{l}\text { Tenaga Kerja } \\
\text { Penjual }\end{array}$ & $\begin{array}{l}\text { Rp. } \\
15.000\end{array}$ & $\begin{array}{l}\text { Rp. } \\
17.500\end{array}$ & $\begin{array}{l}\text { Rp. } \\
20.000\end{array}$ & & & $4,7 \%$ \\
\hline \multicolumn{5}{|c|}{ Rata-rata Biaya Pendukung } & 27.250 & & $34,3 \%$ \\
\hline \multicolumn{5}{|c|}{ Rata-rata Total Biaya Produksi dan Pendukung } & 137.000 & 350000 & $4,3 \%$ \\
\hline & & IVIIaI Ju & a) Datik $\mathrm{K}$ & ai Tambah & & 213.000 & $81,3 \%$ \\
\hline
\end{tabular}

Berdasarkan hasil perhitungan nilai tambah menunjukkan bahwa untuk produksi 1 kain batik dibutuhkan biaya sebesar Rp. 109.750,00 Selanjutnya dibutuhkan biaya penunjang lainnya sebesar Rp. 27.250,00 berdasarkan perhitungan nilai tambah diatas diperoleh total biaya yang dikeluarkan untuk 1 kain batik tulis siap jual sebesar Rp. 137.000,00 Untuk Rata-rata harga jual 1 kain batik tulis yang ada di UD. Ijen Batik sebesar Rp. 350.000,00/potong, maka diperoleh hasil nilai tambah sebesar 213.000,00 atau sebesar 81,3 \%. Hal ini dikarenakan hasil nilai tambah (value added) yang tertinggi diperoleh dari aktivitas penjualan dan pemasaran. Yang artinya sebagian besar pendapatan yang dihasilkan oleh UD. Ijen Batik diperoleh dari hasil penjualan ke wholeseller dan Retail. Karna 
dari hasil penjualan tersebut UD. Ijen Batik dapat menentukan keuntungan yang diinginkan. Suatu aktivitas dikatakan memiliki nilai tambah ketika produk yang dijual memiliki kualitas yang baik, harga yang murah dan pelayan yang baik.

\section{Hasil Analisis SWOT pada UD. Ijen Batik}

Tabel 15. Matriks SWOT pada UD. Ijen Batik di Bondowoso

\begin{tabular}{|c|c|c|}
\hline INTERNAL & $\begin{array}{l}\text { KEKUATAN (S) } \\
\text { 1. UD. Ijen Batik } \\
\text { mempunyai } \\
\text { konsumen yang tetap. } \\
\text { 2. batik di jual dengan } \\
\text { harga yang } \\
\text { terjangkau. } \\
\text { 3. Memiliki tempat } \\
\text { distribusi yang tetap. } \\
\text { 4. Menawarkan produk } \\
\text { batik batik melalui } \\
\text { media elektronik } \\
\text { 5. Bahan baku } \\
\text { berkualitas baik. } \\
\text { 6. Mempunyai motif } \\
\text { batik yang beragam. } \\
\text { 7. Memiliki karyawan } \\
\text { yang berpengalaman. }\end{array}$ & $\begin{array}{l}\text { KELEMAHAN (W) } \\
\text { 1. Jenjang pendidikan yang } \\
\text { dimiliki karyawan masih } \\
\text { rendah. } \\
\text { 2. Kurangnya pelatihan } \\
\text { untuk karyawan. } \\
\text { 3. Sistem pembukuan belum } \\
\text { tersusun secara baik. } \\
\text { 4. Kurangnya modal dalam } \\
\text { pengembangan usaha } \\
\text { 5. Pemasaran belum optimal. } \\
\text { 6. Harga produk yang cukup } \\
\text { tinggi. }\end{array}$ \\
\hline $\begin{array}{l}\text { PELUANG (O) } \\
\text { 1. Daya beli konsumen } \\
\text { terhadap produk batik } \\
\text { 2. Produk batik memiliki } \\
\text { pasar produk yang luas } \\
\text { 3. Kesadaran masyarakat } \\
\text { membudayakan batik } \\
\text { 4. Adanya kebijakan } \\
\text { pemerintah terhadap } \\
\text { produk batik } \\
\text { 5. Minat pelanggan terhadap } \\
\text { produk batik } \\
\text { 6. Kemajuan teknologi } \\
\text { mendukung dalam } \\
\text { kegiatan pemasaran } \\
\text { produk batik } \\
\text { 7. Produk yang dihasilkan } \\
\text { berkualitas batik }\end{array}$ & $\begin{array}{l}\text { STRATEGI S-O } \\
\text { 1. Mempertahankan } \\
\text { pelanggan dengan } \\
\text { menambahn inovasi } \\
\text { motif batik. } \\
\text { 2. Mempertahankan } \\
\text { harga dan kualitas } \\
\text { produk batik. } \\
\text { 3. Mengembangkan } \\
\text { media sosial sebagai } \\
\text { salah satu media } \\
\text { promosi ijen batik } \\
\text { Bondowoso. }\end{array}$ & $\begin{array}{l}\text { STRATEGI W-O } \\
\text { 1. Mengembangkan potensi } \\
\text { karyawan dengan } \\
\text { memberikan pelatihan- } \\
\text { pelatihan. } \\
\text { 2. Memanfaatkan teknologi } \\
\text { dalam pengembangan } \\
\text { sistem akuntansi pada } \\
\text { ijen batik. } \\
\text { 3. Mengencarkan promosi } \\
\text { dan pemasaran batik ke } \\
\text { berbagai relasi. }\end{array}$ \\
\hline $\begin{array}{l}\text { ANCAMAN (T) } \\
\text { 1. Tingginya tingkat } \\
\text { persaingan batik yang ada } \\
\text { di Bondowoso } \\
\text { 2. Banyaknya baju batik } \\
\text { yang sudah jadi yang } \\
\text { harganya jauh lebih } \\
\text { murah daripada kain } \\
\text { batik } \\
\text { 3. Kenaikan harga bahan } \\
\text { baku } \\
\text { 4. Masuknya pesaing baru } \\
\text { pada industri batik di } \\
\text { daerah Bondowoso }\end{array}$ & $\begin{array}{l}\text { STRATEGI S-T } \\
\text { 1. Mempertahankan } \\
\text { harga batik dengan } \\
\text { kualitas yang sama. } \\
\text { 2. Mengembangkan dan } \\
\text { memodifikasi motif } \\
\text { batik tradisional dan } \\
\text { modern. } \\
\text { 3. Menciptakan ciri khas } \\
\text { tersendiri dari } \\
\text { produk batik yang } \\
\text { sejenis. }\end{array}$ & $\begin{array}{l}\text { STRATEGI W-T } \\
\text { 1. Menjalin kerja sama } \\
\text { dengan beberapa penjahit } \\
\text { di sekitar bondowoso. } \\
\text { 2. Menyesuaikan harga jual } \\
\text { batik dengan kualitas } \\
\text { bahan baku. }\end{array}$ \\
\hline
\end{tabular}

21 Asersi: Jurnal Akuntansi Terapan dan Bisnis | Vol. 1, No. 1, 2021, \{12-24\}| ISSN 2807-243X (online version) 


\section{Data Hasil Produksi Batik Pada UD. Ijen Batik}

Dalam pengolahan batik tulis dibutuhkan beberapa bahan baku utama yang meliputi kain mori, lilin atau malam, pewarna dan waterglass serta membutuhkan peralatan yang mendukung untuk proses produksi peralatan tersebut meliputi canting, kompor, panci lorot dan meja gambar. Dalam proses produksi pembuatan batik dimulai dari mendesain gambar atau membuat motif. Langkah selanjutnya adalah melakukan penjiplakan kemudian lakukan membatik sesuai pola, selanjutnya pola di tebalkan menggunakan canting. Proses berikutnya yaitu memberikan warna pada kain mori yang telah di canting, setelah itu melakukan fiksasi dimana fiksasi ini bertujuan untuk mengunci warna yang masuk ke dalam serat agar warna yang dihasilkan tidak mudah luntur. Setelah melakukan fiksasi yaitu proses pengeringan. Untuk proses terakhir yaitu melakukan pelorodan kain mori dengan cara mencelupkan di air panas seperti merebus gunanya agar malam tidak menempel pada kain. Proses terakhir yaitu menjemur kain hingga kering setelah kering dilipat dan di setrika agar terlihat rapi, kain batik yang sudah jadi siap di kemas dan dipasarkan. Tahap manajemen mutu dalam proses pengembangan batik di UD. Ijen Batik biasanya dilakukan dalam banyak tahapan selama kegiatan outbond logistik. Namun di UD Ijen Batik beberapa pengrajin bergantung pada beberapa karyawan untuk memeriksa barang-barang batik. Tak hanya itu pemasaran yang dilakukan UD. Ijen Batik ini sudah menggunakan media sosial untuk mempromosikan hasil produksinya. Konsumen batik tulis di UD. Ijen Batik umumnya terdiri dari wholeseller, retail, dan konsumen akhir. Rata-rata hampir semua barang terjual di wholeseller.

\section{SIMPULAN}

Penelitian ini menyimpulkan rantai nilai pada aktivitas pertama di UD. Ijen Batik Bondowoso meliputi inbound logistik (penyimpanan) diketahui kebutuhan bahan standar pengolahan batik tulis mempunyai jumlah yg bertentangan tergantung bisnis berdasarkan pengrajin, secara global dalam penyimpanan bahan standar batik pada UD. Ijen Batik Bondowoso tidak ditemukan perawatan yg khusus, umumnya para pengrajin hanya meletakkan bahan standar pada gudang. Dalam pengelolaan bahan baku pada UD. Ijen Batik Bondowoso memakai sistem First In First Out (FIFO) dimana bahan baku yg diterima terlebih dahulu dipakai lebih dulu. Selanjutnya operasi (produksi), pada umumnya UD. Ijen Batik Bondowoso memproduksi batiknya setiap hari dan dilakukan secara manual mulai dari sistem desainnya hingga sampai pada pengemasan produk batik untuk kegiatan selanjutnya yaitu pengemasan hingga pendistribusian (outbound logistik) dimana UD. Ijen Batik umumnya dalam pendistribusian UD. Ijen Batik melibatkan distributor seperti pada penjahit-penjahit di sekitar daerah Bondowoso. Dalam pendistribusiannya UD. Ijen Batik memiliki tim dalam proses pengemasannya tersendiri. Kegiatan selanjutnya yaitu pemasaran dan penjualan dimana UD. Ijen Batik ini menggunakan media sosial untuk mempromosikan hasil produksinya tak hanya itu UD. Ijen Batik ini sering mengikuti kegiatan event sekaligus mempromosikan hasil produk batiknya sehingga produk batik yang mereka hasilkan bisa di kenal diseluruh indonesia bahkan luar negeri. Selanjutnya aktivitas yang terakhir yaitu aktivitas pelayanan, bahwasannya UD. Ijen Batik memberikan pelayanan kepada konsumen seperti perbaikan produk cacat contohnya pada saat batik yang dihasilkan kurang memuaskan atau tidak sesuai keinginan konsumen. Dari sini bisa dkatakan bahwa UD. Ijen Batik sudah melakukan yang terbaik agar memuaskan konsumen. Dari hasil interview menyatakan bahwa saat ini UD. Ijen Batik bisa dikatakan jarang sekali mendapatkan komplain dari konsumen. Berdasarkan analisis nilai tambah yg sudah dilakukan peneliti, bisa diketahui bahwa 
nilai tambah dalam produk batik tulis pada UD. Ijen Batik sebesar Rp. $213.000,00 /$ per unit atau 81,3 \%. Hal ini karena Nilai tambah (value added) yang tertinggi diperoleh dari aktivitas penjualan dan pemasaran. Yang artinya sebagian besar pendapatan yang dihasilkan oleh UD. Ijen Batik diperoleh dari hasil penjualan ke wholeseller dan Retail. Karna dari hasil penjualan tersebut UD. Ijen Batik dapat menentukan keuntungan yang diinginkan.

Setelah mengetahui aktivitas utama rantai nilai sebagai upaya untuk meningkatkan keunggulan kompetitif peneliti juga melakukan analisis SWOT gunanya untuk mengetahui kekuatan, kelemahan, peluang dan ancaman apa saja yang ada di UD. Ijen Batik Bondowoso. Dapat dilihat dari matriks internal yang berupa kekuatan dan kelemahan selaras dengan hasil in-depth interview (wawancara mendalam) yang dilakukan dengan pemilik UD. Ijen Batik Bondowoso, bahwasanya yang menjadi kekuatan utama pada UD. Ijen Batik adalah memiliki macam-macam produk meskipun memiliki harga batik yang cukup tinggi UD. Ijn Batik mampu mempertahankan pelanggan yang dimilikinya. Di lihat dari kelemahannya UD. Ijen Batik Bondowoso perlu mengadakan pelatihan khusus untuk karyawan yang pendidikannya masih rendah tak hanya itu untuk penyusunan sistem pembukuan belum tersusun dengan baik. Untuk matriks eksternal yang berupa peluang dan ancaman. Ijen Batik Bondowoso perlu untuk melakukan inovasi produk yang lebih unik dan berbeda dengan produk pesaing lainnya yang membuat konsumen terkesan untuk membeli produk batik pada UD. Ijen Batik, Bondowoso. Tak hanya itu dari semua produk UD. Ijen Batik yang memiliki keunggulan yaitu pada batik tulis dengan motif blue fire.

Berdasarkan analisis yang telah dilakukan pada UD. Ijen Batik, secara keseluruhan UD. Ijen Batik sudah memiliki aktivitas rantai nilai yang cukup baik. Akan tetapi UD. Ijen Batik juga perlu meningkatkan kinerja aktivitas rantai nilai untuk memperkuat persaingan di pasar. Seperti lebih memperluas jaringan distribusi ke berbagai daerah yang tidak hanya di daerah Bondowoso saja sehingga produk yang dihasilkan UD. Ijen Batik dikenal di berbagai daerah. Temuan penelitian ini diharapkan dapat bermanfaat bagi peneliti terdahulu sebagai bahan perbandingan dan acuan untuk penelitian selanjutnya, khususnya di bidang analisis rantai nilai sebagai sarana untuk memperoleh keunggulan bersaing. Peneliti selanjutnya akan melakukan penelitian analisis rantai nilai pada operasi sekunder atau pendukung perusahaan. untuk pengumpulan data peneliti selanjutnya diharapkan ditunjang dengan wawancara dengan sumber yang lebih berkompeten sehingga hasil penelitian lebih akurat. Hal itu tentu menjadikan keberhasilan dalam membangun serta meningkatkan keunggulan yang kompetitif. Sehingga penelitian ini bermanfaat bagi perusahaan.

\section{DAFTAR RUJUKAN}

Ayu, P. I., Susbiyani, A., \& Fitriya, E. (2020). Analisis Rantai Nilai (Value Chain Analisis) Sebagai Upaya Untuk Meningkatkan Keunggulan Kompetitif Bagi Perusahaan.

Freddy, R. (2009). Analisis SWOT Teknik Membedah Kasus Bisnis. Gramedia Pustaka Umum.

Kotler, P., \& Gary, A. (2012). Prinsip-prinsip Pemasaran (13th ed.). Erlangga.

Nikmah, R. N. (2017). Analisis Implementasi Value Chain dalam meningkatkan daya saing pada produk handy craft di perusahaan Marto Putro Rotan Welahan Jepara. 50-96.

Porter, M. E. (2013). Strategi Bersaing (Competitive Strategy). Kharisma Publishing Group. 
S, F. (2010). ( Analisis Rantai Nilai ) Untuk Keunggulan Kompetitif Melalui Keunggulan Biaya. Jurnal Ekonom, 12(1).

Saryono. (2010). Metode Penelitian Kualitatif. Alfabeta.

Sugiyono. (2017). Metode Penelitian Kuantitaif, Kualitatif, dan R\&D. Alfabeta.

Suharti, \& Yuliawati, E. (2015). Pengembangan Strategi Peningkatan Daya Saing Produk Batik dengan Menggunakan Analisis Value Chain. Jurnal MATRIK, XV(2), 11-19.

Tindi, I. (2001). Value Chain Analysis and Competitive Advantage At Mayfair Group Companies In Kenya. Journal of General Management, 27(1), 18-42. https://doi.org/10.1177/030630700102700102

Widarsono, A. (1999). ( Analisi Stratejik Rantai Nilai ): Universitas Stuttgart, 1-27. 